\title{
A MOBILIDADE NO CONTEXTO DAS DINÂMICAS CITADINAS: UMA ABORDAGEM DIALÉTICA COMO FERRAMENTA DE COMPREENSÃO
}

\author{
VENÂNCIO, Marluce W. (1); \\ DUAILIBE, Andréa C. S. C. (2)
}

(1) Universidade Estadual do Maranhão - UEMA, Dra. e-mail: marlucewall@gmail.com

(2) Universidade Estadual do Maranhão - UEMA, MSc.

e-mail: andrea.duailibe@gmail.com

\begin{abstract}
RESUMO
O tema da mobilidade compõe parte desta ampla discussão do VII ENEAC - VII Encontro Nacional de Ergonomia do Ambiente Construído e VIII Seminário Brasileiro de Acessibilidade Integral, como parte do contexto das dinâmicas do ambiente construído da cidade. $O$ artigo retoma a importância da abordagem dialética contida na metodologia de ateliê de projeto aplicada a experiências desenvolvidas em sala de aula. O conteúdo pretende reforçar a ideia de que a tríade ensino-pesquisa-extensão deve caminhar junta no que se refere às questões urbanas e que o exercício de projeto é multidisciplinar e multimétodos.
\end{abstract}

Palavras chave: mobilidade; dinâmicas urbanas; metodologia de ateliê de projeto.

\begin{abstract}
The theme of mobility is part of this broad discussion of the VII ENEAC - VII National Meeting on Ergonomics of the Built Environment and VIII Brazilian Seminar on Integral Accessibility, as part of the context of the dynamics of the built environment of the city. The article retakes the importance of the dialectical approach contained in the project atelier methodology applied to experiences developed in the classroom. The content intends to reinforce the idea that the teaching-research-extension triad must go hand in hand with regard to urban issues and that the project exercise is multidisciplinary and multi-methods.
\end{abstract}

Keywords: mobility; urban dynamics; project atelier methodology.

\section{INTRODUÇÃO}

O presente artigo pretende tratar a questão da mobilidade como parte do contexto das dinâmicas do ambiente construído da cidade, a partir de uma abordagem que vem sendo explorada nos últimos dois anos tanto na disciplina de Equipamentos Sociais Urbanos da Universidade Estadual do Maranhão, como em trabalhos de pesquisa e extensão que seguem essa linha de pensamento do Curso de arquitetura e Urbanismo da Universidade Estadual do Maranhão.

Primeiramente, importante situar do ponto de vista pedagógico, que a abordagem de ateliê de projeto foi adotada para a referida disciplina, de modo que o conteúdo programático e as atividades recebem um tratamento diferente dos métodos convencionais de ensino. Tendo em conta o período em que o corpo discente se situa (alunos entre o $7^{\circ}$ e o $8^{\circ}$ períodos), 0 método busca instigar o processo participativo e inclusivo da turma nos problemas 


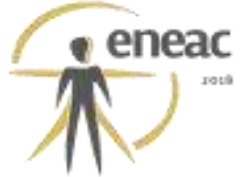

propostos, estimular a aceitação das inquietações como prováveis hipóteses a serem testadas, além de tirar partido das provocações que confrontam teorias dogmáticas frente aos experimentos empíricos.

São escolhidas situações que constituem o repertório da cidade, sob a forma de recortes territoriais e temporais no espaço urbano de São Luís, em condições que revelam oportunidades, algumas potencialmente vantajosas, outras, problemáticas.

Antes de se apegar às teorias, um certo tom de provocação é adotado para as discussões em sala, na medida em que se lida com objetos de natureza complexa. As cidades são vistas como estruturas dinâmicas, orgânicas e multidimensionais que, a cada dia, assumem um pouco mais das características que o empirismo interveniente lhes impõe.

A abordagem de ateliê de projeto se remete ao método dialético de ensino-aprendizagem, e segue um eixo tripartite, em que se tem, de acordo com Vasconcellos (1992): (i) mobilização para o conhecimento; (ii) construção do conhecimento; (iii) elaboração da síntese do conhecimento.

Mais do que promover uma imersão em conteúdos teóricos, meras sínteses abstratas aos olhos incipientes do aluno, a disciplina trata, principalmente, de exercitar o olhar meticuloso do arquiteto urbanista sobre o objeto de estudo. Um primeiro olhar, ainda que embaçado por empirismos, carregado de "pré-conceitos" acerca de uma sucessão de mitos urbanos simplistas de causa-e-efeito; pois é essa primeira impressão, afoita, que precisa ser registrada, descrita e mapeada, levando ao primeiro exercício de construção da(s) hipótese(s).

Não se pretende aqui o estabelecimento de receitas, nem mesmo fixar um passo-a-passo rumo à soluções ideais, definitivas, frente a um contexto de decisões de projeto de resultados incertos, posto que não se percebe convergência nem mesmo entre os organismos de planejamento e gestão das cidades, em especial, em São Luís.

O conhecimento vai sendo construído à medida que as questões emergem, de modo que o aporte teórico é disponibilizado juntamente com o desenrolar das atividades. A intenção é que a busca por teorias de apoio sirva ao oferecimento de soluções eficazes; não raro, autores e teorias são combinados, de forma a gerar respostas e soluções para situações não tão incomuns. De forma paralela, autores de base são abordados no decorrer das atividades, a oferecer suporte aos grupos.

O tema da mobilidade compõe parte desta ampla discussão, e neste sentido, a relevância do presente artigo está no propósito de contribuir para as áreas de conhecimento da Ergonomia do Ambiente Construído e da Acessibilidade Integral, na medida em que expõe o resultado de estratégias de projeto com foco na vitalidade urbana.

\section{CONSTRUÇÃO DE UM MÉTODO}

Inicialmente, foi proposto aos alunos um exercício que tomou por base mapas setoriais, imagens fotográficas e recentes filmagens de diferentes pontos da cidade de Toulouse/FR, todas referentes ao ano de 2017 (Figuras 1 e 2). Com o material em mãos e dada a impossibilidade de acessar de forma presencial os lugares, os alunos são estimulados a identificar aspectos relevantes relativos à constituição espacial dos ambientes disponibilizados. Configurações de paisagem, formas, volumes, céu visível, relações de escala, acessibilidade, cores, dinâmicas possíveis, densidades, conexões, intermodalidades, materiais, detalhes e tantos outros elementos que consigam identificar e interpretar, a partir do material disponibilizado. 


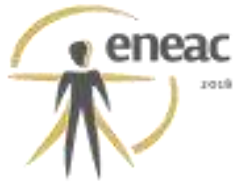

Figura 01 - Jeanne d'Arc - Toulouse, França

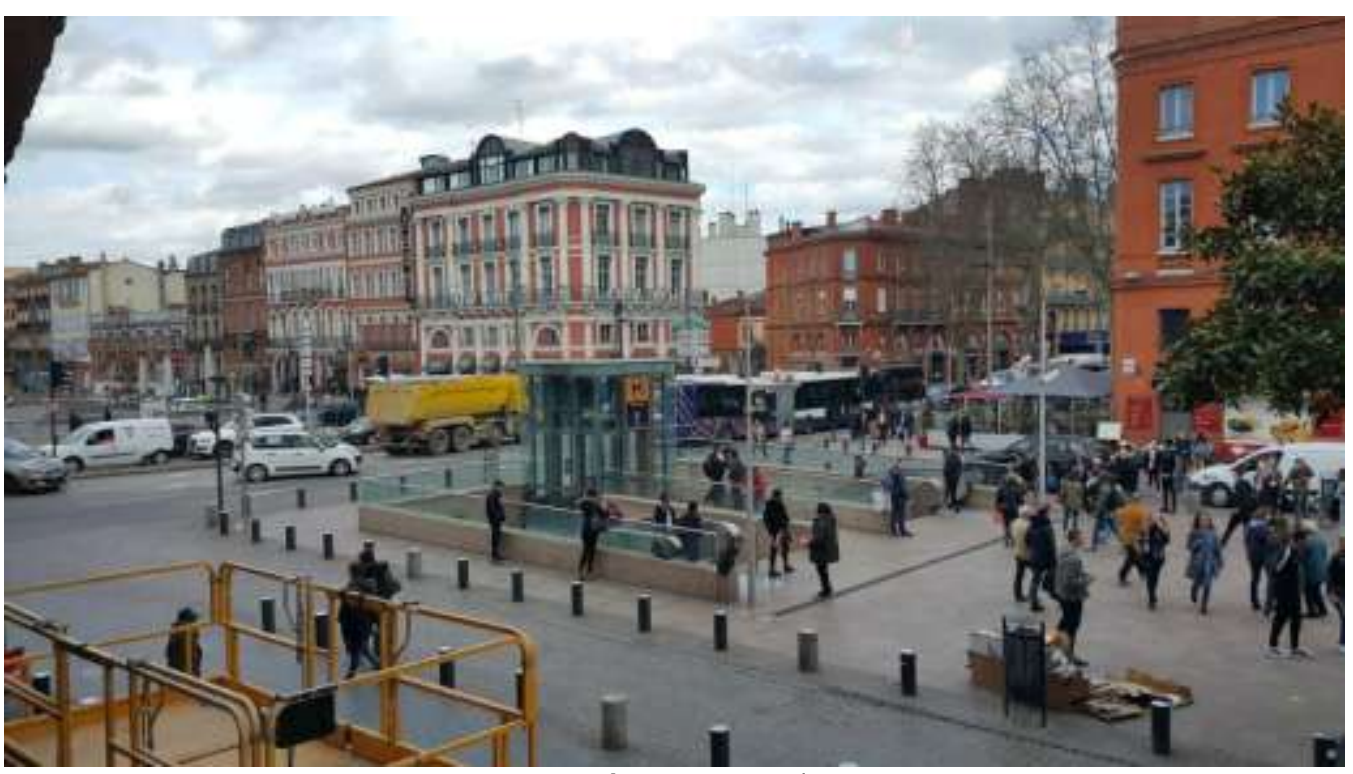

Fonte: Própria, março/ 2017

Figura 02 - Jeanne d'Arc - Toulouse, França

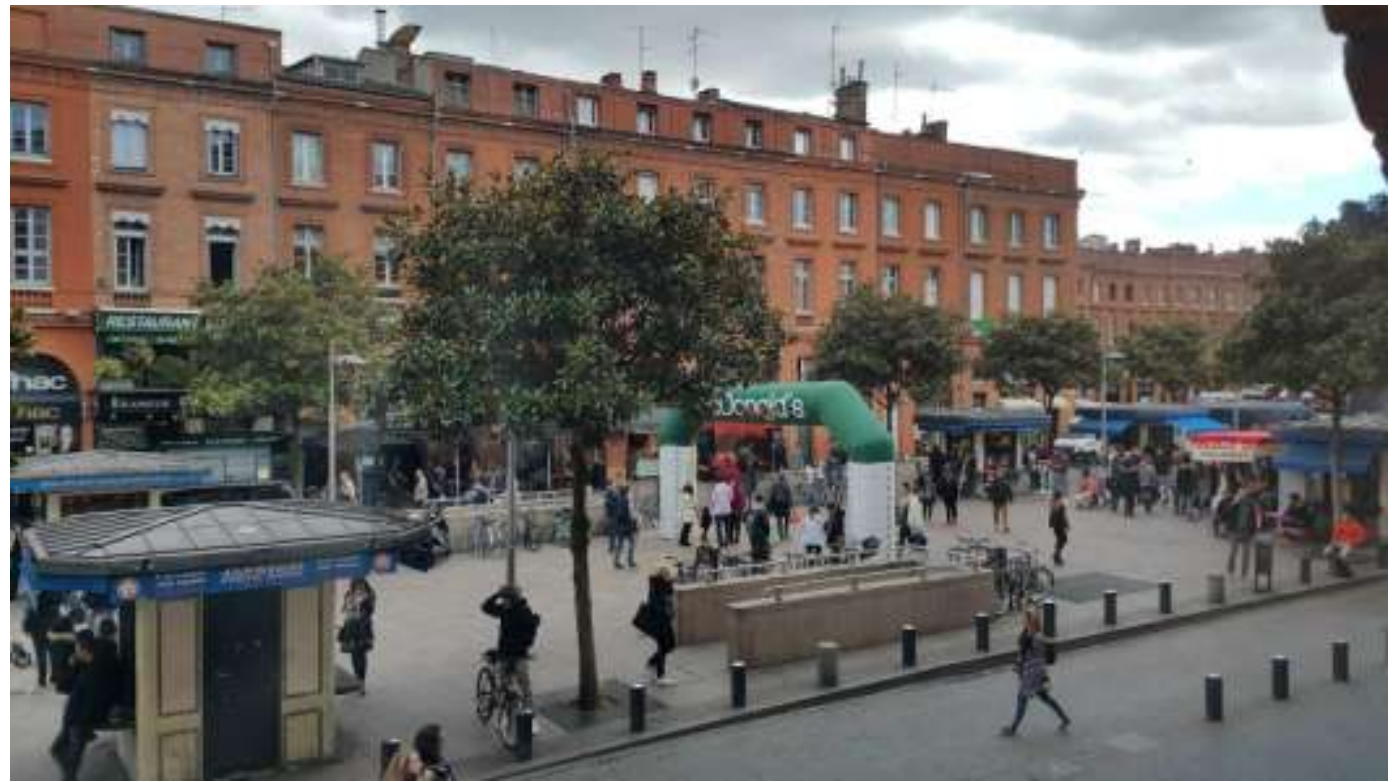

Fonte: Própria, março/ 2017

Textos e croquis são produzidos e têm início os relatos de cada equipe, de modo que todos tenham a oportunidade de ouvir uns aos outros, com pausas para questionamentos e posicionamentos, quer sejam convergentes ou divergentes. De forma espontânea, surgem os "porquês", os "talvez", os "vemos que", os "imaginamos que seja por causa de", e outros comentários e questionamentos que precedem a uma hipótese; é o início de uma longa jornada repleta de incômodas "inquietações" e rumo à uma longa lista de oportunidades. Esse primeiro exercício pode ser encarado como espécie de aquecimento para o próximo.

A essa altura, algumas dessas inquietações preliminares foram propostas em sala e discutidas com as equipes: (i) $\mathrm{O}$ sentido de mobilidade seria compreendido como uma 


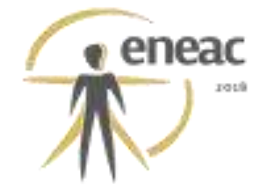

categoria, como eixo de conexão multidimensional ou como outra coisa; qual o seu significado, portanto? (ii) Seria possível isolar os elementos que compõem as dinâmicas urbanas em camadas temáticas de forma que fosse possível determinar suas influências e capacidades? (iii) Seriam esses elementos de composição comuns a todas as dinâmicas citadinas?

A partir das inquietações, o foco se assenta na compreensão da mobilidade, na conceituação, e em suas dimensões e seus paradigmas. Das discussões em sala, é possível apreender percepções intrigantes a partir das narrativas, que acabam por associar as políticas de promoção à mobilidade unicamente à midiática ideia de "fluidez no trânsito de veículos", dentre outras. Uma clara contradição entre a retórica acadêmica e a concretização da política urbana nesse quesito, situação que é vivenciada pelos próprios estudantes.

Longe de refletir conceitos aprendidos nas salas de aula do Curso de Arquitetura e Urbanismo da UEMA, a forte referência nas mídias oficiais e a vivência das constantes alterações do traçado urbano de São Luís, confrontam o discurso acadêmico e em algum momento, a incongruência entre a teoria a prática se evidencia.

De forma resumida, tem-se na constatação da ineficiência dos meios de transporte públicos ofertados, nos enclaves impostos à intermodalidade e nas condições de (in)acessibilidade, a consolidação do paradigma da necessidade de aquisição de veículos particulares (símbolo de status social) e, naturalmente, a sua proliferação, em especial, das motocicletas.

Neste cenário de sucessivos equívocos, ruídos até certo modo, explicáveis de diferentes formas, desde a matriz econômica, passando por questões de ordem social, educacional, cultural, política, e tantas outras, que não cabem aqui serem elencadas, a proposta da disciplina é exercitar o olhar sobre as dinâmicas existentes, isolando momentaneamente a mobilidade e a sua natureza, conduzindo os alunos ao experimento que vai desde a observação acurada da realidade, à representação gráfica, à análise e, finalmente, à proposição.

\section{MOBILIDADE COMO INCLUSÃO}

A partir daqui, retoma-se a abordagem da primeira inquietação. De acordo com a Cartilha do Ministério das Cidades para a Mobilidade Urbana (2005), temos preliminarmente, que:

A mobilidade urbana é um atributo das cidades e se refere à facilidade de deslocamentos de pessoas e bens no espaço urbano. Tais deslocamentos são feitos através de veículos, vias e toda a infra-estrutura (vias, calçadas, etc) que possibilitam esse ir e vir cotidiano. Isso significa que a mobilidade urbana é mais do que o que chamamos de transporte urbano, ou seja, mais do que o conjunto de serviços e meios de deslocamento de pessoas e bens. É o resultado da interação entre os deslocamentos de pessoas e bens com a cidade. (Instituto Polis, p. 4).

A mobilidade é um atributo que influencia e é influenciado pelas demais categorias que compõem a cidade, de tal sorte que pensar a mobilidade urbana é, também, pensar sobre como se organizar os usos e a ocupação do solo urbano.

Nesse sentido, tem-se, na promoção da mobilidade, a melhor forma de se garantir o acesso das pessoas e bens ao que a cidade oferece (locais de emprego, escolas, hospitais, praças e áreas de lazer), e não apenas pensar os meios de transporte e a velocidade com que se dá o trânsito dos veículos em suas diferentes categorias. 


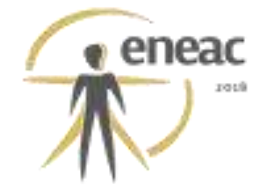

Até aqui, pode-se concluir que o sentido de mobilidade compreende diferentes formas: como uma categoria, dentro de um modelo citadino semi-reticular, na síntese de Christopher Alexander (1965), integrado por diferentes elementos constitutivos, posicionados, conforme suas categorias lhes permite, conectados entre si, ao mesmo tempo em que pode ser compreendida como uma sucessão de eixos de conexão multidimensional, que interligam diferentes pontos posicionados no espaço-tempo (Figura 03). Mas isso, provavelmente não é tudo. Tal percepção pode sustentar a estruturação de uma resposta para a segunda inquietação.

Figura 03 - Análise do contexto e síntese da forma proposta por Alexander, C. (1965)

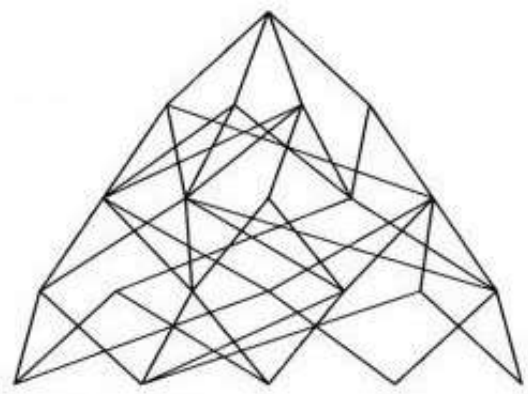

SEMI-RETICULA

Fonte: PEIXE, M.C. et TAVARES, S.(2018)

Percebe-se, assim, que é possível isolar a categoria mobilidade do ponto de vista conceitual, e até representá-la graficamente, mas não é possível operá-la de forma dissociada das dinâmicas que ela promove entre os diferentes elementos compositivos da cidade. A mobilidade, por sua natureza multidimensional, assume, simultaneamente, dimensões temporais e espaciais, transcendendo o aspecto físico de vias públicas, ruas, avenidas, etc. Tem-se na mobilidade a dimensão maior da relação espaço-tempo na cidade.

Retoma-se, então, à primeira inquietação: seria realmente possível isolar os elementos que compõem as dinâmicas urbanas em camadas temáticas de forma que fosse possível determinar suas influências e capacidades? E quais os efeitos práticos desse procedimento para um diagnóstico mais preciso?

Longe de seguir com uma narrativa generalista, a presente exposição se utiliza de estudos de caso tratados como exercícios em sala já concluídos, todos a partir de recortes temporais e territoriais preestabelecidos, o que permitiu às equipes explorar os diferentes ambientes que compõem esses territórios no decorrer dos interstícios letivos de 2017.

\section{MOBILIDADE E CONECTIVIDADE}

A partir desses recortes, serão pontuadas as teorias que serviram de suporte à cada ação, respostas possíveis às múltiplas situações de causa e efeito que interagem entre si.

De acordo com Roland Barthes (2011), e, em tradução livre, "o objetivo de toda a atividade estruturalista, seja ela reflexiva ou poética, é reconstruir um 'objeto' de modo a manifestar suas regras de funcionamento [...] Estrutura é, portanto, um simulacrum do objeto, mas um simulacrum direto e interessado, uma vez que o objeto expõe algo que permanece invisível ou, se alguém preferir, não inteligível no objeto. O homem estruturalista capta o real, 0 decompõe e depois o reconstrói”. (BARTHES, 2011) Esse raciocínio traduz, em parte, a percepção dos idos anos 60 , das concepções de espaço como sistemas interligados. 


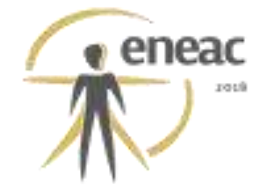

De um modo geral, os elementos de composição urbana são comuns a quase todas as dinâmicas citadinas, no entanto, Jan Gehl (2013) tem abordado, de forma objetiva, questões que são fundamentais à qualidade de vida na cidade. São questões que versam, acima de tudo, sobre a vitalidade urbana.

Nas cinco a seis últimas décadas, a produção de cidades se transformou de forma radical, e processos de adensamento e urbanização em massa podem ser observados e sentidos com velocidade e escala sem precedentes. Evoluiu-se para uma lógica de produção de cidade que alguns autores têm categorizado como waves of mass urbanization ${ }^{1}$.

Milhões de pessoas são "adicionadas" ao contexto urbano, dia após dia, transfiguradas em personas, entes ativos dentro dos diferentes processos inerentes a esse ambiente. Os ambientes urbanos têm revelado a natureza dessas mudanças, como palco de um conjunto de fenômenos de repercussões transnacionais, que assumiu subdimensões locais e, assume ainda, diferentes formatos, conforme a cidade se insere no contexto das redes urbanas.

O diagrama semi-reticular proposto por Alexander (1965) ganhou dimensões que extrapolam a folha de papel sobre a qual foi impresso, e um sentido de universalidade pode ser admitido à imagem por suas infinitas possibilidades de interação. Acrescentem-se ao contexto elementos não representáveis graficamente, as ondas de energia, inclusive solar, as telecomunicações, as redes wifi, que movimentam e articulam as soluções para a mobilidade, e então lidamos com uma representação gráfica distinta e renovada da versão exposta até então.

Soluções de projeto que se refletem na escala dos espaços, nas soluções de mobilidade, nas dinâmicas que favorecem ou não a vitalidade, na sustentabilidade, na sensação de segurança nas áreas urbanas, na valorização dos espaços públicos, nas possibilidades de expressão individual e coletiva, na percepção da paisagem que pode ser apreendida ao nível do observador.

O fator tempo/distância impõe condições logísticas complexas, que permitem tanto a intermodalidade e o controle social nos ambientes criados, como a interconexão entre seus diferentes elementos, garantindo dinâmicas saudáveis e eficientes do ponto de vista da vitalidade urbana.

A mobilidade assume, com efeito, uma dimensão que vai muito além das garantias legais e facilidades ergonômicas do ir e vir de um cidadão comum, já que o sentido de produtividade e eficiência energética, eles se acoplam com muita naturalidade ao processo de concepção e produção de cidade.

Os exercícios em sala de aula têm buscado explorar essas dinâmicas presentes no ambiente urbano e a sua influência no desenvolvimento das denominadas redes de network urbano, que se estruturam sobre o território geograficamente (dimensão material) e virtualmente (imaterial), em que pese a complexa rede de conectividade inerente à era pósglobalização ${ }^{2}$, de tal forma que uma não subsiste sem a outra.

\footnotetext{
1 Ondas de urbanização em massa, processos descritos como intervenções diretas e multidimensionais, com metas claras do ponto de vista da ocupação, mas consequências não tão previsíveis ou de fácil controle.
}

${ }^{2}$ December 2015 RWP15-078 Visit the HKS Faculty Research Working Paper Series at: https://research.hks.harvard.edu/publications/workingpapers/Index.aspx 


\section{A MATRIZ TEMÁTICA COMO ESTRATÉGIA DE ABORDAGEM}

Os processos de expansão da cidade seguem concomitantes à essa discussão e mantêm o foco nas estratégias de (hiper)adensamento e nos investimentos massivos no que tange o uso e ocupação do solo e à comunicabilidade ${ }^{3}$. O fenômeno resultante desse modelo gestão de cidade sedimenta-se a partir de elevados investimentos vocacionados a explorar, cada vez mais, as capacidades do território citadino em suas diferentes dimensões e temporalidades. Um modelo de expansão que tem implicado em ondas de adensamento que, em muitas cidades brasileiras, supera a capacidade de oferta de infraestrutura de um modo geral, em especial, restringindo a mobilidade.

O método da elaboração de matrizes temáticas é uma estratégia utilizada como forma de dissecar as estruturas elementares geradoras de dinâmicas, e se inspira no pensamento estruturalista francês, também datado nos anos 60 . Em essência, busca compreender de que forma as dinâmicas são construídas no espaço-tempo, sua versatilidade e volatilidade uma vez que admite elementos imateriais à sua composição.

A estratégia parte de um pressuposto de caráter empírico, segundo o qual percebe-se que mesmo diante das dinâmicas urbanas aparentemente mais caóticas, existe uma (des)ordem que a rege. A desconstrução seguida de reconstrução, através de representação gráfica das camadas dos temas que as envolve, tem permitido um olhar mais racional sobre o território em estudo. Partindo de um mapa repleto de informações, legendas multitemas, observado sem o estabelecimento de critérios prévios para a análise, surgem as matrizes temáticas, registros apartados, seguindo um checklist de elementos de composição perceptíveis naquele território selecionado.

Para que o exercício possa adequar carga horária acadêmica com conteúdo programático, é estabelecido recorte preciso espaço-tempo, ainda que isso traga repercussão nos resultados finais, do ponto de vista da abrangência e das causalidades incidentes. No entanto, por se tratar de exercício acadêmico, o experimento permite que, nesse interregno, os estudantes pesquisadores possam explorar uma gama mais ampla de elementos, com início, meio e fim de atividade condizentes com os objetivos da disciplina.

As equipes são estruturadas, de modo que tenham condições de observação e discussão em conjunto. Aos poucos, as impressões vão sendo mapeadas e hierarquizadas conforme códigos e valores estabelecidos pelos alunos, primeiramente num único mapa. Inspirado na metodologia de avaliação do ambiente construído (normalmente, aplicada a edifícios) apropria-se ao processo a abordagem walkthrough, a partir da qual é feito o registro dos diferentes elementos que compõem o território selecionado, os usos, as formas, as dinâmicas, num esforço conjunto de pôr ordem, de planificar o que é dinâmico e multidimensional.

A seguir, utilizaremos um exemplo de atividade realizada com a turma de Equipamentos Sociais Urbanos durante o segundo semestre de 2017, já concluída. O método se desenrola em quatro a cinco fases, em média, a depender do objeto escolhido.

No primeiro momento se deu a seleção e a delimitação de território (Figura 04) entendido como recorte espaço-tempo, a partir de um corredor principal na cidade de São Luís. Significa dizer que a área de estudo é demarcada e o trabalho de observação e análise se dará num determinado número de dias úteis num intervalo de tempo pré-fixado. No caso específico, segunda a sexta-feira (conforme disponibilidade e plano de trabalho de cada equipe) entre os horários de 13:30h às 16:00h, durante um período determinado, previsto no calendário acadêmico.

3 O vocábulo pretende denotar o caráter de potência, refletido em situações rotineiras que demandam capacidade, fluidez, rapidez e eficiência nas comunicações. 


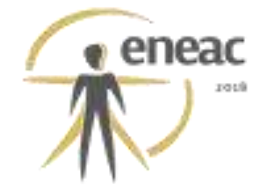

Figura 04 - Seleção de área sobre Googlemaps. A equipe registra preliminarmente, nessa plataforma, os elementos observados de percurso walkthrough realizado em trecho selecionado da Avenida Castelo Branco, Bairro São Francisco, São Luís - MA.

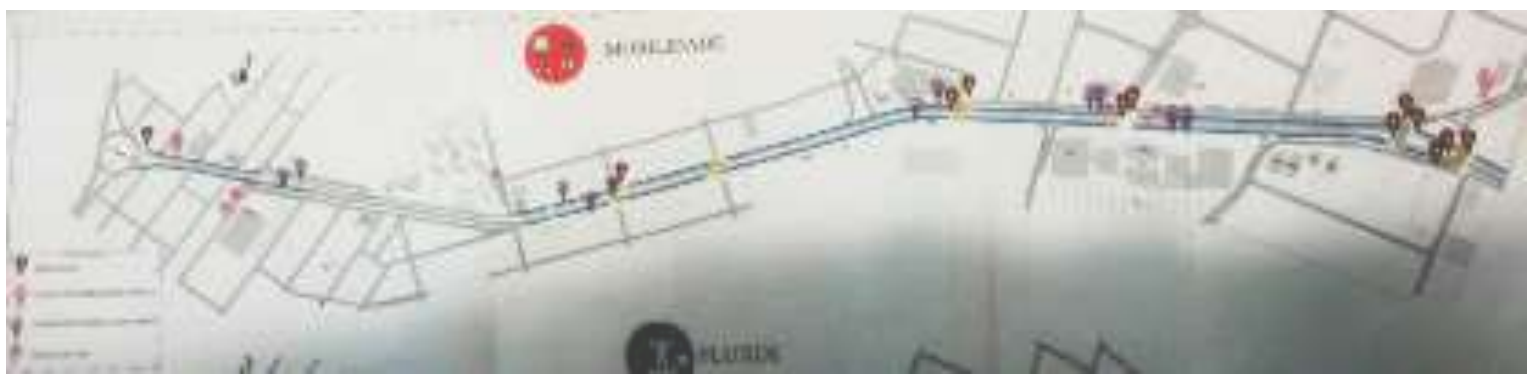

Fonte: Equipe 02 alunos de Disciplina Equipamentos Sociais Urbanos no $2^{\circ}{ }^{\circ}$ semestre de 2017

A fase é uma mistura desenhos realizados à mão (lápis de cor) sobre referenciais de mapas oriundos do Googlemaps, de forma que possam localizar-se e também, localizar os marcos que referenciam o relatório preliminar da equipe. Também as fotografias são sobrepostas ao mapa preliminar, realçando aspectos considerados relevantes.

Paralelamente, foi feita a exploração dos elementos que compõem a vitalidade urbana, no entanto, o recorte aqui exposto foi a mobilidade, tópico explorado também, em sala de aula.

Alguns autores são frequentemente abordados na forma de textos, com leitura coletiva e comentada, também em sala. Nessa fase, Jacobs (2013), Lynch (2006) e a recente publicação de Netto, $V$ et al (2017) servem de apoio acerca do tema da vitalidade urbana. Outros artigos também serviram de suporte.

Figura 05 - Parte dos registros fotográficos de percurso walkthrough realizado em trecho selecionado da Avenida Castelo Branco, Bairro São Francisco, São Luís - MA

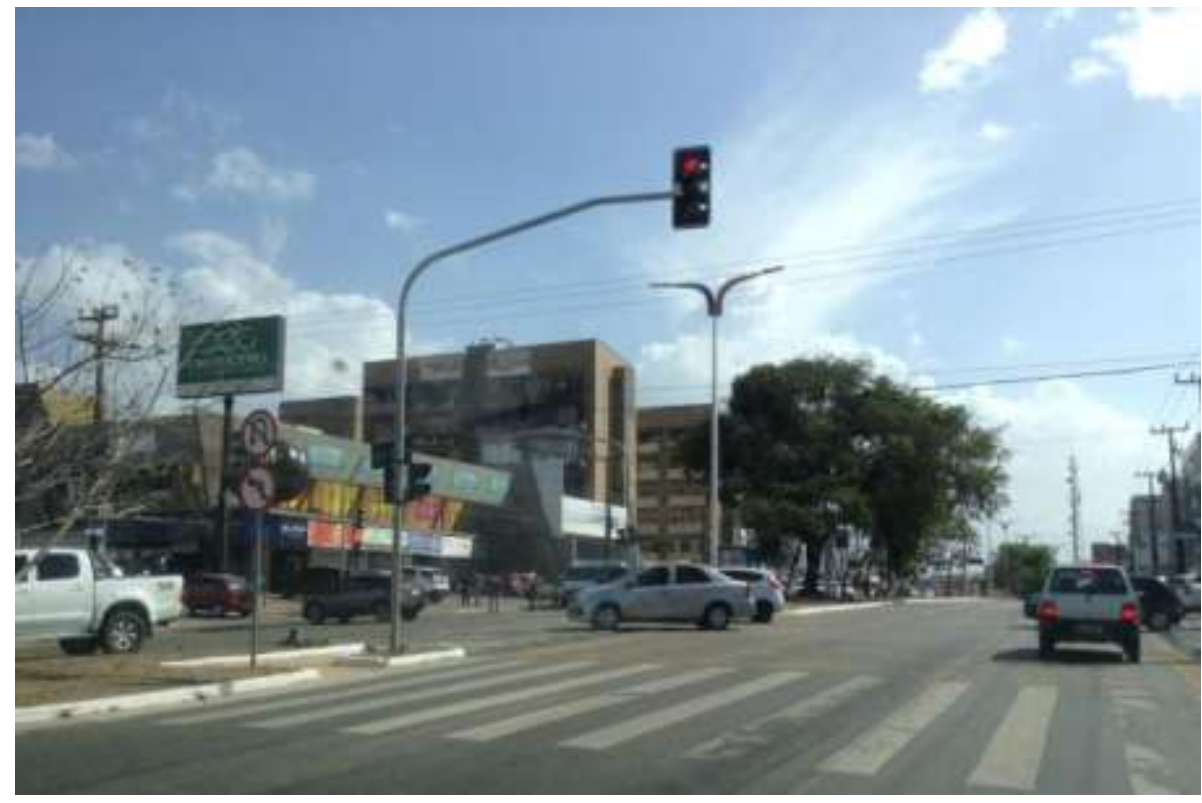

Fonte: Equipe 02 alunos de Disciplina Equipamentos Sociais Urbanos no 2º semestre de 2017 


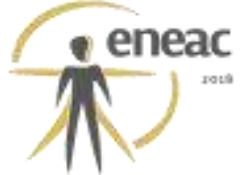

Figura 06 - Parte dos registros fotográficos de percurso walkthrough realizado em trecho selecionado da Avenida Castelo Branco, Bairro São Francisco, São Luís - MA.

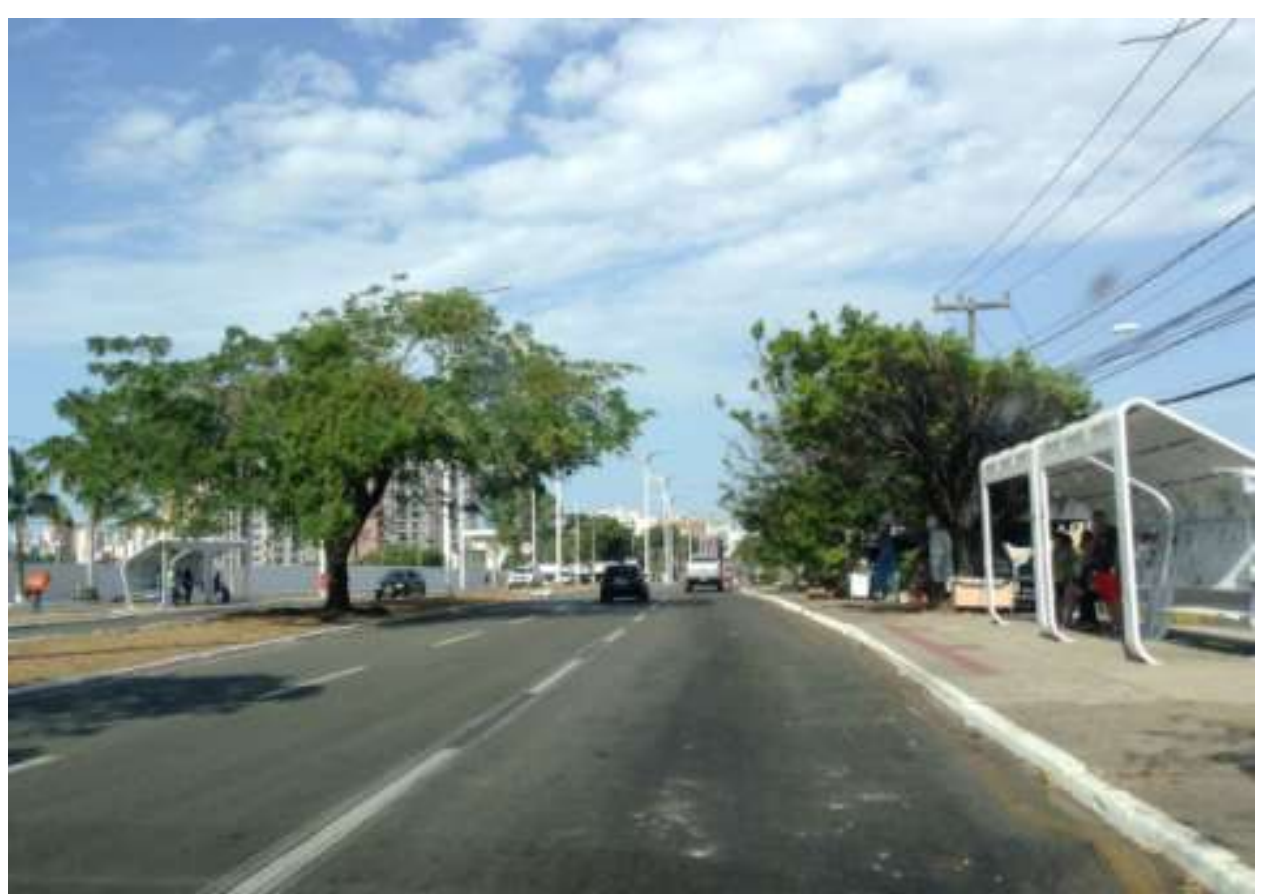

Fonte: Equipe 02 alunos de Disciplina Equipamentos Sociais Urbanos no $2^{\circ}$ semestre de 2017

Como focalizamos o composto mobilidade, as equipes se ocupam, nesta etapa, em elencar elementos de composição de dinâmicas e suas respectivas interfaces. Isso somente fica possível a partir da geração das matrizes temáticas, estratégia de decomposição de mapas, isolando os temas graficamente.

O trabalho de produção dos desenhos é executado à mão, utilizando recursos de desenho como lápis de cor e hidrocores; o tempo de produção é também tempo de reflexão. De um mapa preliminar complexo, vê-se um desdobrar em diferentes outros, mais simples, denominados matrizes temáticas. As legendas vão sendo também separadas, de modo que as equipes se concentram em representar de forma simples e coerente as informações coletadas em campo.

Figura 07 - Desenho esquemático que explica a conformação das matrizes temáticas
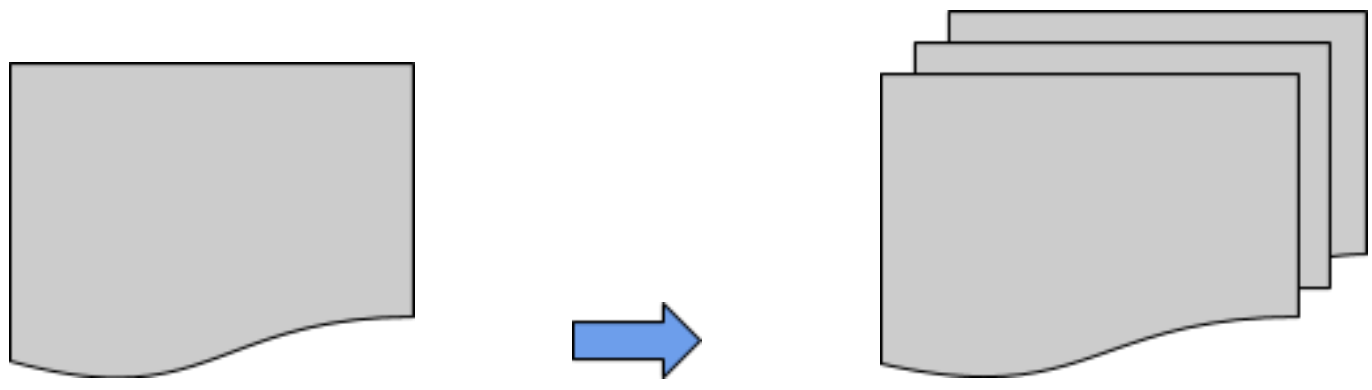


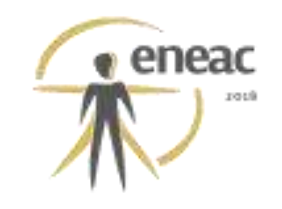

A atividade em si, apesar de simples, é bastante trabalhosa, mesmo considerando a execução em equipes. Nota-se, no decorrer desta etapa, uma maior interação entre os alunos com relação à atividade proposta. As discussões são mais consistentes, mesclando aspectos formais de representação gráfica e, principalmente, quais matrizes serão isoladas e se, destas, haverá necessidade de subdivisões.

O papel do professor é de orientador, observar as dinâmicas de grupo e a evolução de cada etapa. Curiosamente, alunos de mesmo nível ou período, trabalhando sobre uma mesma plataforma (território selecionado), têm comportamento similar em alguns momentos, mas muito diferentes em outros, em especial quando chegam às fases de seleção de temas, hierarquização de problemas e potencialidades e nas tomadas de decisão. (LASSANCE, 2007) A interação com o orientador, nessa fase, não é imposta; é demandada pelos alunos, quando sentem necessidade. $E$ as atividades seguem seu rumo, todas a respeitar um cronograma prefixado de conclusão de etapas; nesse caso, a rigidez é relativa, sendo o deadline das entregas para lançamento de notas, os marcos principais.

A mobilidade gera muitas discussões e algumas equipes chegam a optar por separar itens relativos aos pedestres (densidades, comportamentos, percursos, qualidade de calçadas, pontos de ônibus, semáforos) dos que compõem o trânsito de veículos (sentido, volume, pontos de convergência), mesmo compreendendo que tudo funciona de forma sistêmica. Assim, sentem-se mais seguros em analisar e diagnosticar alguns dados de forma isolada.

Concluídas as matrizes, a próxima etapa será de sobreposição. Fase rica, de muitas possibilidades de combinações, muitos debates dentro das equipes (alguns inflamados) quanto a quais matrizes melhor se associam de modo a refletir com clareza as hipóteses previamente lançadas nos relatórios de percurso walkthrough.

Tudo segue tranquilo, até o momento em que as equipes vão se dando conta de que, ao sobreporem três, e às vezes, cinco matrizes, algumas de suas hipóteses se invalidam. Isto porque, eventualmente, condições que haviam sido reduzidas à questões simples de causae-efeito, passam a ser explicadas pela incidência de múltiplos agentes, alguns, inclusive, imateriais. O grau de complexidade nas leituras cresce e fortalece as narrativas.

\section{CONSIDERAÇÕES FINAIS}

O entendimento da força dos agentes incidentes justifica tanto a abordagem estruturalista como a adoção do método de construção do conhecimento a partir da compreensão da realidade. Os mecanismos estratégicos se complementam e sua aplicabilidade, guardadas as especificidades de cada objeto de estudo, tem demonstrado resultados bastante interessantes quando avaliados em conjunto.

A natureza dialética do método permite que as atividades se dêem em equipes de alunos, condição que permite além da aprendizagem, o exercício da pesquisa e o manuseio de diferentes mecanismos estratégicos com vistas a solução de problemas. Os resultados dos processos são compartilhados em apresentações em sala em todas as suas fases, mantidas a autonomia das equipes em entender, raciocinar, decidir e propor sobre o objeto, que é comum a todos.

O método da elaboração de matrizes temáticas tem se mostrado uma estratégia eficaz, utilizada como forma de dissecar as estruturas elementares geradoras de dinâmicas urbanas, embora fique claro que trata-se um procedimento ainda em evolução, e que portanto, ainda está em aprimoramento nos contextos de sala de aula e de ateliê de projeto, uma vez que mira compreender cada vez mais as dinâmicas e suas performances. 


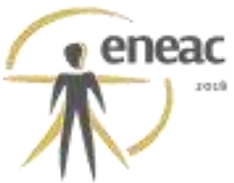

\section{REFERÊNCIAS BIBLIOGRÁFICAS}

Barthes. R. 2011. The structuralist activity. Em Valena, T. et al (Eds.), Structuralism Reloaded (pp. 22-24). Stuttgart: Axel Menges.

BRASIL. Ministério das Cidades. Instituto Polis. Mobilidade é desenvolvimento urbano. Cartilha. Brasília, DF, 2005, 36 p. Disponível em: <http://www.polis.org.br/uploads/922/922.pdf.> Acesso em: 25 nov. 2017.

GEHL, Jan. Cidades para pessoas. São Paulo: Perspectiva, 2013.

JACOBS, Jane. Morte e vida de grandes cidades. 3.ed. São Paulo: Editora WMF Martins Fontes, 2011.

LYNCH, Kevin. A imagem da cidade. São Paulo: Ed Martins Fontes, 2006.

LASSANCE, Guilherme Carlos. O projeto como argumento: consequências para o ensino e para a pesquisa em arquitetura. In: DUARTE, Cristiane Rose. et al (Org.). O lugar do projeto: no ensino e na pesquisa em arquitetura e urbanismo. Rio de Janeiro: Contra Capa Livraria, 2007.

MIRANDA, Juliana Torres de. A relação entre teoria e prática na arquitetura e seu ensino: teoria reflexiva e projeto experimental. In: DUARTE, Cristiane Rose. et al (Org.). 0 lugar do projeto: no ensino e na pesquisa em arquitetura e urbanismo. Rio de Janeiro: Contra Capa Livraria, 2007.

MORAES NETTO, Vinicius. A cidade como resultado: consequências de escolhas arquitetônicas. In: et al (Org.). Efeitos da arquitetura: os impactos da urbanização contemporânea no

Brasil. Brasília: FRBH, 2017.p.25-49.

PEIXE, Marco Aurélio; TAVARES, Sergio. A linguagem de padrões de Christopher Alexander: parâmetros projetuais para a humanização do espaço construído. Disponível em: <http://www.http://vitruvius.com.br.> Acesso em: 25 nov. 2017.

SABOYA, Renato T. de. Fatores morfológicos da vitalidade urbana: uma investigação sobre o tipo arquitetônico e seus efeitos, 2015. In: et al (Org.). Efeitos da arquitetura: os impactos da urbanização contemporânea no Brasil. Brasília: FRBH, 2017.p.51-70.

Fatores morfológicos da vitalidade urbana - parte 2: acessibilidade. ArchDaily Brasil, [S.I.], fev. 2017. Disponível em: <http://www.archdaily.com.br> Acesso em: 23 nov. 2017.

Condições para a vitalidade urbana \#1 - densidade. ArchDaily Brasil, [S.I.], nov. 2012. Disponível em: <http://www.archdaily.com.br> Acesso em: 23 nov. 2017.

Condições para a vitalidade urbana \#2 - proximidades e distâncias na malha de ruas, ArchDaily Brasil, [S.I.], dez. 2012. Disponível em: <http://www.archdaily.com.br> Acesso em: 23 nov. 2017.

Condições para a vitalidade urbana \#4 - permeabilidade visual, ArchDaily Brasil, [S.I.], jun. 2013. Disponível em: <http://www.archdaily.com.br> Acesso em: 23 nov. 2017.

VARGAS, Heliana Comin. Ensino/aprendizagem em arquitetura e urbanismo: mitos e métodos. In: DUARTE, Cristiane Rose. et al (Org.). O lugar do projeto: no ensino e na pesquisa em arquitetura e urbanismo. Rio de Janeiro: Contra Capa Livraria, 2007.

VARGAS, Júlio Celso. Forma urbana e transporte a pé: mobilidade, caminhabilidade, vitalidade In: et al (Org.). Efeitos da arquitetura: os impactos da urbanização contemporânea no Brasil.

Brasília: FRBH, 2017.p.71- 89. 